\section{Spatial Network Analysis The Decision-Making Process}

Seung Ra

Oklahoma State University
Data-driven research methods of analyzing and generating urban space reflect professional developments in the field of architecture, using urban data analytics as a driving force for the decision-making process. Urban data analytic methods help us to see and understand the city via the flow of spatial data. How might we look to alternative influences to improve the built environment? This paper focuses on the topic of Urban Network Analysis; nurturing an effective decision-making process by making invisible urban patterns visible through geo-spatial data. The associated research project created a platform to participate in the active relationship of urban form and its organization within the natural and built environments. The investigation aimed to provide goals for the future direction of urban planning and design guidelines. The computational analysis tools employed here demonstrate how to utilize geospatial data to analyze street networks, to create case studies of pattern and formation, and to expand our knowledge of relevant issues - social, political, economic, environmental, and spatial. ${ }^{1}$

Instead of being given a problem, the project team was proactively seeking the problem, based in this case on Geographic Information System (GIS data. Creating meaningful solution to these issues is the role of designers and the future of architecture. In our problem seeking, we examined issues of accessibility, walkability, and pedestrian and vehicular movement by using computational analytic methods. ${ }^{2}$ The research helped us to understand the city via the flow of spatial data and its analysis applications. Using these tools, we simulated the growth of the city and analyzed it by looking at urban patterns. Several fundamental questions arose: In what ways do elements of urban form begin to affect an urban network? Are there other urban phenomena that contribute to forming an urban network? In cities where growth rate is rapid, transportation systems pose a challenge. How does spatial structuring of the city influence it? Is the analysis valuable? If so, why and who could benefit from its application? How could those factors begin to affect the analysis interpreted by the network analysis?

\section{MOTIVATION}

Developing diverse perspectives of the design research process is a common challenge for market-driven practice. As a hallmark of architectural pedagogy, studio-based education focuses on taking a holistic approach to creativity and diversity of thought. In reality, not all professional practice can invest in a studio-based research phase within the scope and budget of a typical project. Therefore, it is crucial to incorporate such expertise in the academic environment.

The recent implementation of the new transportation system, Oklahoma City Streetcar, is a significant improvement of the city's infrastructure as a crucial part of the city-wide urban development plan, Metropolitan Area Projects Plan 3 (MAPS3 (Figure ${ }^{3}$ It was necessary to study the active relationship of urban form and its organization within the built environment. Oklahoma State University School of Architecture and Edmon Low Library Maps and Spatial Data are excited to share a data-driven research project: Spatial 


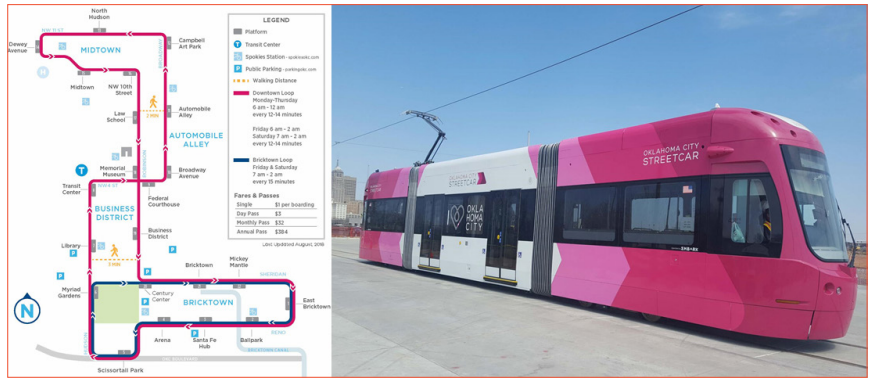

Figure 1. Oklahoma City Streetcar (OKC EMBARK).

Network Analysis for Oklahoma City Streetcar. In collaboration with the Oklahoma City Planning Department, the interdisciplinary team created a model of the area surrounding the route of the Oklahoma City Streetcar. This simulation will be useful in design and decision-making processes and will also help influence future urban planning guidelines.

This interdisciplinary project provided clues for developing an effective platform to bring diverse entities together. The level of complexity in the future of the profession demands an asynchronous planning approach to accommodate various aspects and disciplines in current urban issues. Data-driven research methods of analyzing and generating urban space are not the only solution to incorporating the expertise of professional practice into the academic environment. In recent years, the fields of architecture and GIS have moved closer in alignment. The primary motivation for this shift was the inadequacy of the common scales of analysis. Traditionally, GIS in an urban setting worked at the scale of the region, city, and perhaps the neighborhood, whereas architecture generally focused on the site level. The interdisciplinary research between academia and practice strengthens the capacity to expand knowledge and insights; each has something unique to contribute. The exchange between the two entities allows us to blur lines between academia and practice; thus the sphere of architecture will expand.

\section{RESEARCH OVERVIEW}

In collaboration with the Oklahoma City Planning Department and the University Library Maps and Spatial Data, the interdisciplinary team provided extensive research using urban network analysis tools and geographic information systems data. Spatial Network Analysis for Oklahoma City Streetcar focused on the transportation of the streetcar and its effects on the urban environment and how the mode of transportation will become a catalyst for future urban planning. These fixed modes of transportation bring positive impact toward the economy, environment, and urban growth. Presumably, this associated urban transportation system will influence urban spatial structure, the set of relationships, and interaction between urban form and people. ${ }^{4}$ This evolution of urban form by infrastructure creates a new linkage within the city. Three entities were used in the research report: the measurement of network dimension via population density, assessing the environmental quality of the infrastructure in stops, and block generation by algorithmic modelling.

The project delivered studies on how the future expansion of Streetcars could transform the cityscape for the environment and enhance economically feasible planning strategies. In order to simulate the impact of the new streetcar system, the various networks were analyzed including accessibility, service area, and proximity. There were four initial questions for the project: To what extent does the environment affect the streetcar's viability? What are the demographics of the streetcar and how can it appeal to a wider audience? How does our perception of OKC's block and population change with the new streetcar addition? What elements define a block and how do they define an urban network?

\section{NETWORK DIMENSION AS POPULATION DENSITY}

Urban Topological Analysis and Accessibility provided ecological remediation of existing urban areas and reexamined the current

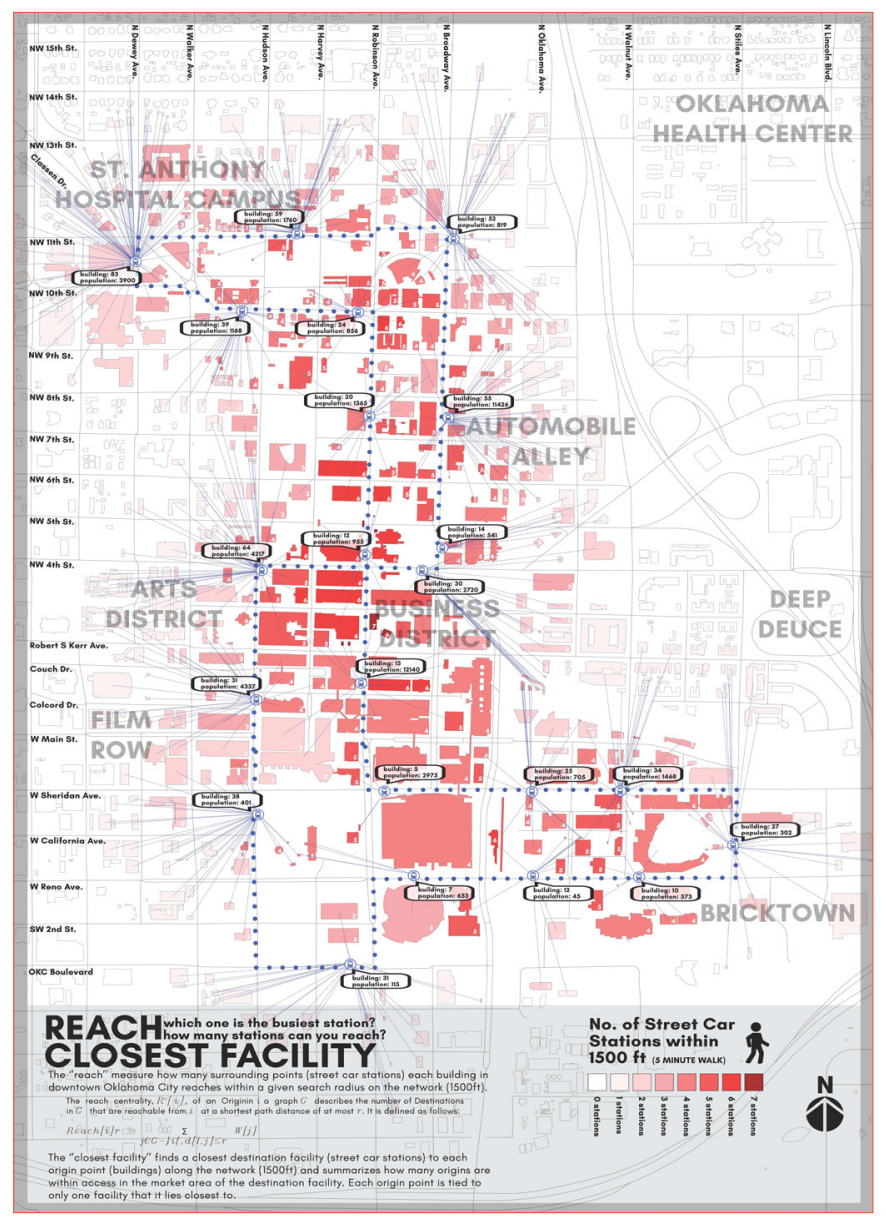

Figure 2. REACH / CLOSEST FACILITY ANALYSIS ${ }^{5}$

This diagram shows "Reach Analysis", how many stops the users can reach from any given building and "Closest Facility Analysis", to measures service area of each stop. 
course of urban renewal strategies. The project's main investigation was to study the active relationship of transportation and urban form and its organization within the built environment, focusing on the Oklahoma City Streetcar. In order to simulate the impact of the new streetcar system, the network analysis included an accessibility study, service area study, and facility proximity study. These elements of studies were directed through various urban simulations How many surrounding destinations could be reached from the location within a given network radius (Figure 2), based on the types of destinations (transit, businesses, and residences)? This measurement is effected by the users (commuter flow) and gravitational forces (streetcar stops) (Figure 3).

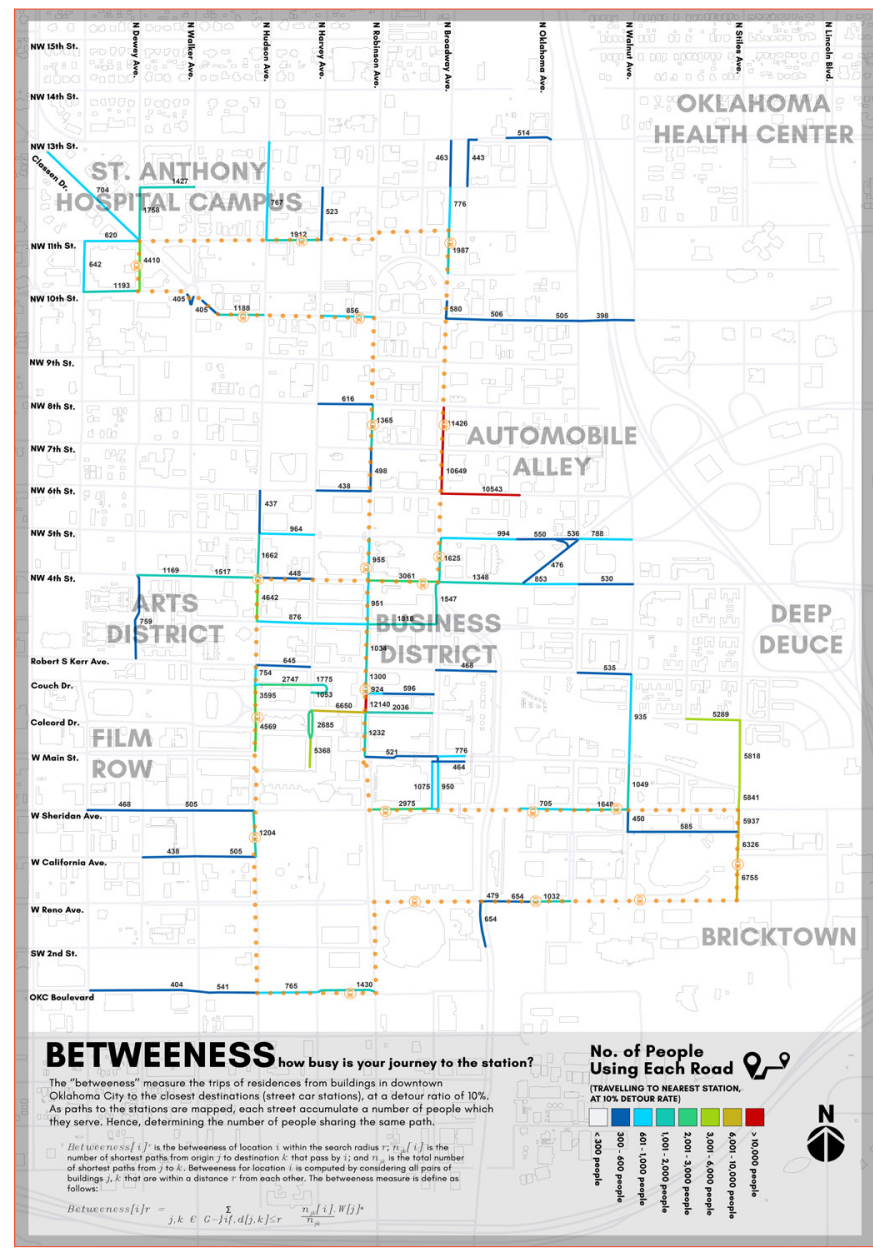

Figure 3. BETWEENNESS ANALYSIS ${ }^{6}$

This diagram shows "Betweenness Analysis" which measures congestion of each street. This diagram illustrated "How busy is your journey to the streetcar stops? from users' perspective. Also, it reveals how service areas can be more disbursed evenly across the city scape and could serve greater population via future expansion.

The quantitative impact of the streetcar discloses how the city changes and responds to field conditions and invisible forces such as economics, culture, and infrastructure. Focusing on researching spatial relationships between OKC streetcar and its population allowed us to answer how the relationship ultimately will impact future planning. In order to study the movement of people, mapping the location of a population at any given time is key to simulating their behavior and facilitating future growth. Particularly, the results in analyzing building per population, in this case business/employment density, are an estimation of who commutes to OKC versus people who live and work in the area. Our methodology and process of data collection comes from a 2018 block census of the working population of OKC. ${ }^{7}$

\begin{tabular}{|c|c|c|c|}
\hline 1164 & 2952 & 0.000811 & 0.002774 \\
\hline 2089 & 1821 & 0.001033 & 0.001246 \\
\hline 1799 & 472 & 0.00072 & 0.000638 \\
\hline 15127 & 1240 & 0.001839 & 0.001285 \\
\hline 5100 & 374 & 0.003652 & 0.000614 \\
\hline 2261 & 879 & 0.002023 & 0.001418 \\
\hline \multirow[t]{2}{*}{572} & 9235 & 0.000787 & 0.003256 \\
\hline & zone building area & zone population & zone population factor \\
\hline $\begin{array}{l}\mathrm{DT}_{\mathrm{p}}= \\
\mathrm{T}_{\mathrm{a}}= \\
\mathrm{S}_{\mathrm{p}}= \\
\mathrm{B}_{\mathrm{a}}= \\
\mathrm{I}_{\mathrm{p}}=\end{array}$ & & $\begin{array}{l}\text { Day Time } \\
\text { Total Block } \\
\text { Population per } \\
\text { Building } \\
\text { Inferred }\end{array}$ & $\begin{array}{l}\text { Population } \\
\text { Area } \\
\text { Sq. Foot } \\
\text { Area } \\
\text { Population }\end{array}$ \\
\hline & formula variable & & \\
\hline
\end{tabular}

Figure 4. NETWORK DIMENSION AS POPULATION DENSITY

$$
\begin{aligned}
& \mathrm{Sp}(\mathrm{Ba})=\mathrm{Ip} \\
& \mathrm{DTp} / \mathrm{Ta}=\mathrm{Sp}
\end{aligned}
$$

DTp = Daytime Population

$\mathrm{Ta}=$ Total Block Area $\quad \mathrm{Sp}=$ Population $/ \mathrm{SqFt}$ $\mathrm{Ba}=$ Building Area I $=$ Inferred Population

The first part of this equation generates a ratio of the average people per square foot which then allows us to apply that multiplier to the square footage of each independent building within the given block area. The total daytime population was taken from seven central block census data sets. The total area of each block was calculated through the summation of each building within the blocks total square footage (floor print area* number of floors)

To see viability and service conditions, we used a volumetric methodology which includes total building area of each block. In order to divide the total population of each block, we developed a multiplier for people per square foot. Equations to calculate population are found in Figure 4.

Through this analysis, we found there were strong relationships between the loops coverage, stop placement, and the distribution of the daytime population of downtown OKC (Figure 5). Most business and commercial destinations studied at this scale are within walking distance of this loop. Considering the population of downtown OKC

is mostly commuters, the streetcar would be under high traffic during 


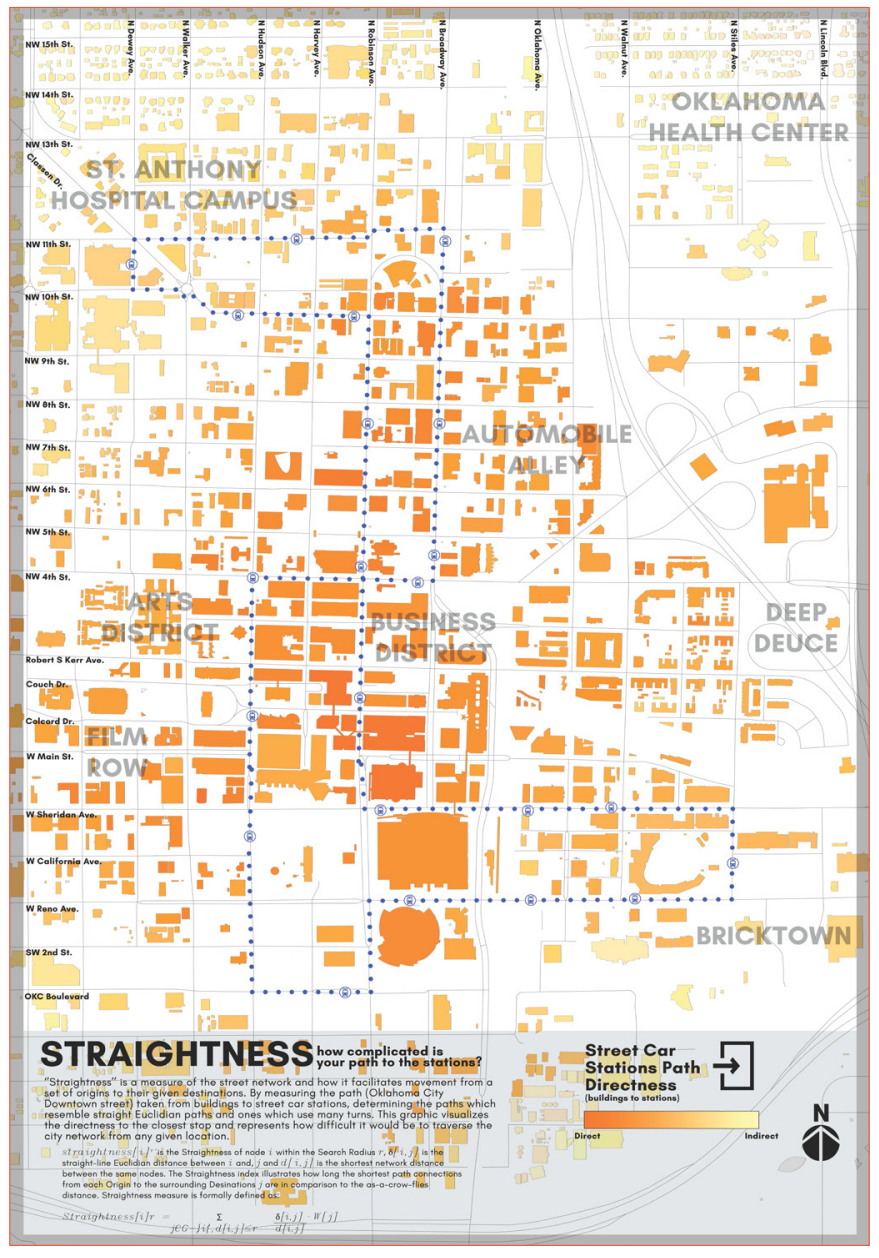

Figure 5. STRAIGHTNESS ${ }^{8}$

This diagram shows "Straightness" as an accessibility measurement which represents how complicated a user's path is to the nearest street car stop. Faded colors indicate several turns required to reach their destination which shows relationships between coverage of the streetcar and the daytime working population. Most businesses and commercial destinations are within walking distance. Beyond the scale of commercial use areas, the streetcar seems to have little impact, compared to existing bus routes with more extensive and broad reaching area.

the daytime, while at night the usage would decrease. The orientation and reach of the current street car aligns with several districts of downtown and successfully ties the different commercial uses of downtown together. However, beyond this scale the streetcar seems to have little impact.

\section{AGGREGATE DIMENSION AS ENVIRONMENTAL ASSESSMENT OF STOPS}

For environmental analysis, the research team sought to understand the environmental climatic conditions surrounding the OKC streetcar throughout the year, and how the climate change would factor in the use of Oklahoma City streetcar. In our analysis, we only looked at 8 out of 22 stops, but it began to show patterns of how much exposure these stops have, by using the data provided by the Oklahoma City planning department. The wind is predominantly out of the southeast. Referencing Figure 6, the blue color represents the base speed that was set for the test. The green is a higher velocity and red is the highest velocity based on how the wind reacts to the buildings around it. Some stops could potentially be very exposed to the wind and could potentially have an effect on the popularity of riders in that area. Using this study we could potentially determine different proposed shelters for each stop based on the degree of wind impacts.

For the current phase of the streetcar, these environmental factors affect the intensity of usage and comfort of urban occupants. Areas investigated include wind and solar analysis. In wind analysis research, computational fluid design base simulations were conducted to identify wind intensity at each individual stop by using Flow by Autodesk. The simulation showed how the natural environment affects pedestrian-level wind comfort due to pedestrian-level wind speeds in different locations relatively. The results show that more southern stops are exposed to high intensity winds than northern counterparts. Beyond these results, there are also potential issues: sheer uncomfortableness, spread of trash, or spread of pollutants and other allergens. From an alternative perspective, the wind is not entirely negative. Some stops require an increase of wind flow as the air might be stale and shows places where we want this to be increased. For sun analysis, the simulation showed exposure and degree of intensity of the sun at different stops. A large majority of stops have high intensity sun exposure during the summer months, and would benefit from additional shading devices.

\section{QUALITATIVE DIMENSION: BLOCK GENERATIVE MODELLING}

Urban form was investigated by reviewing selected areas within the streetcar route to see how the streetcar shapes and influences elements of a city block. We used a generative modeling tool (DeCodingSpaces Toolbox for Grasshopperto look at the speculative quality of block development around southern portions of the city. ${ }^{9}$ Block Generative Modelling enabled us to study a speculative transformation of those areas directly adjacent to the streetcar. Utilizing computational urban analysis tools, we produced various options of theoretical development of downtown OKC to see how we could maximize the streetcar and public transit to encourage development and improve mobility in the city. Keeping in mind categories of land-use, street typologies, and existing and future event centers, we provided one suggestion of how downtown OKC might grow into the future. This installment does not aim to provide extreme detail. It is strictly a general idea, based on the information provided by OKC Planning Commission, our own knowledge of Oklahoma City, and software to thoroughly control and rapidly produce urban streets and masses. By manipulated block FAR and designated block heights, the project generated random results with control methods. We began by increasing the density of the Southern downtown area, as it is currently severely underdeveloped. The varying density with alternative zoning provides valuable clues to potential applications of these patterns to envision 


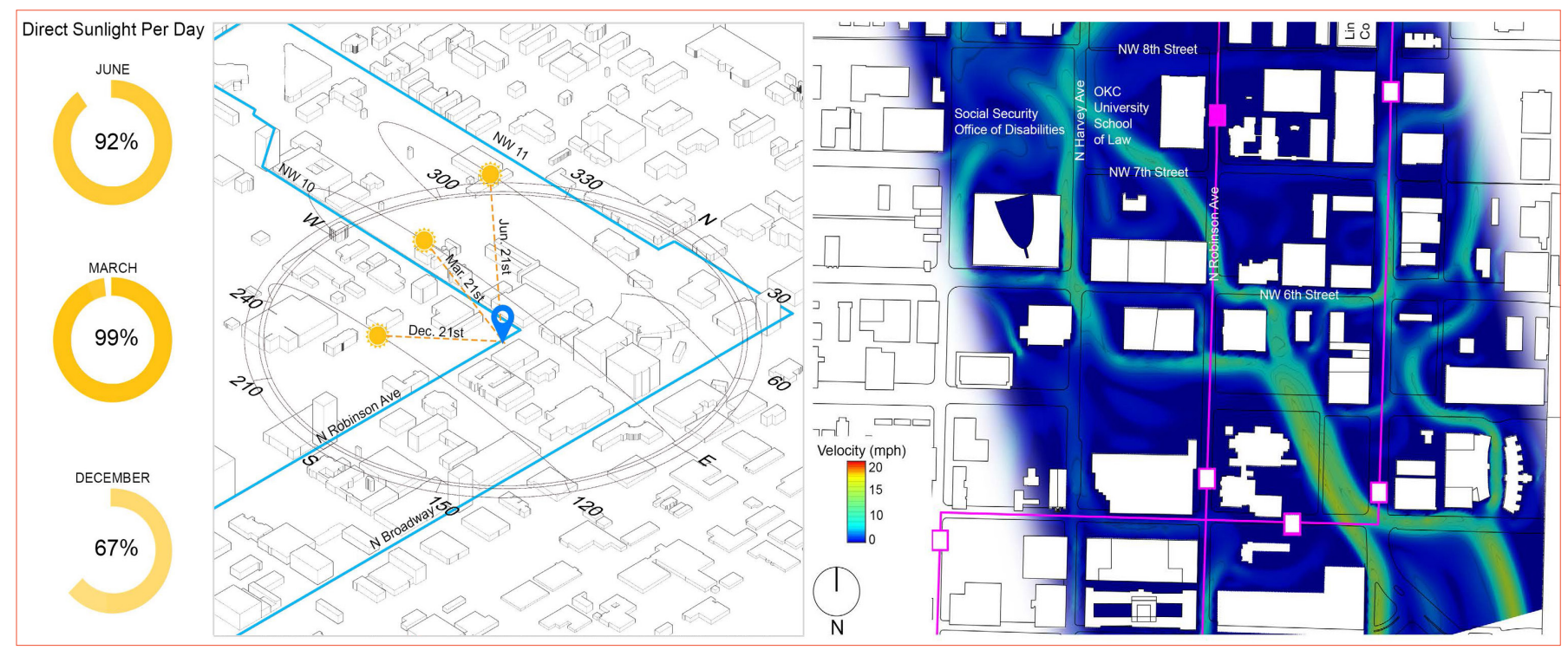

Figure 6. ENVIRONMENTAL ASSESSMENT OF STOPS

The magenta color represents the streetcar stops and route.

future development. ${ }^{10}$

In rethinking downtown, one of the first tools at our disposal was street generation. OKC today is largely laid out on a grid. Built areas of downtown are effectively beholden to this condition, but a significant swath of land along the south and west extremities of downtown are almost blank. We established basic parameters to begin and further increased control factors as the street networks were generated. Among the first parameters was respect for the existing street grid. While this did not align street networks into cardinal directions, the grid's presence can still be seen in the iterations provided. Another parameter was block opacity. For a pedestrian city, it is not enough to provide only sidewalks. Rather than monolithic blocks, the urban environment should vary between open and dense. Another consideration pertinent to the project was streetcar stops. In evaluating suitable street networks, visibility from streetcar stops and paths was an influencing factor. Thus, if blocks were oriented predominantly parallel to streetcar paths or stations, the station became a control point that factored into new street generation. The succeeding images are an initial iteration (in magenta), and a refined adjustment (in cyan) to demonstrate the mentioned factors (Figure 7). These should be considered demonstrations of possible street layouts, as the program can generate entirely new versions without changing the input data.
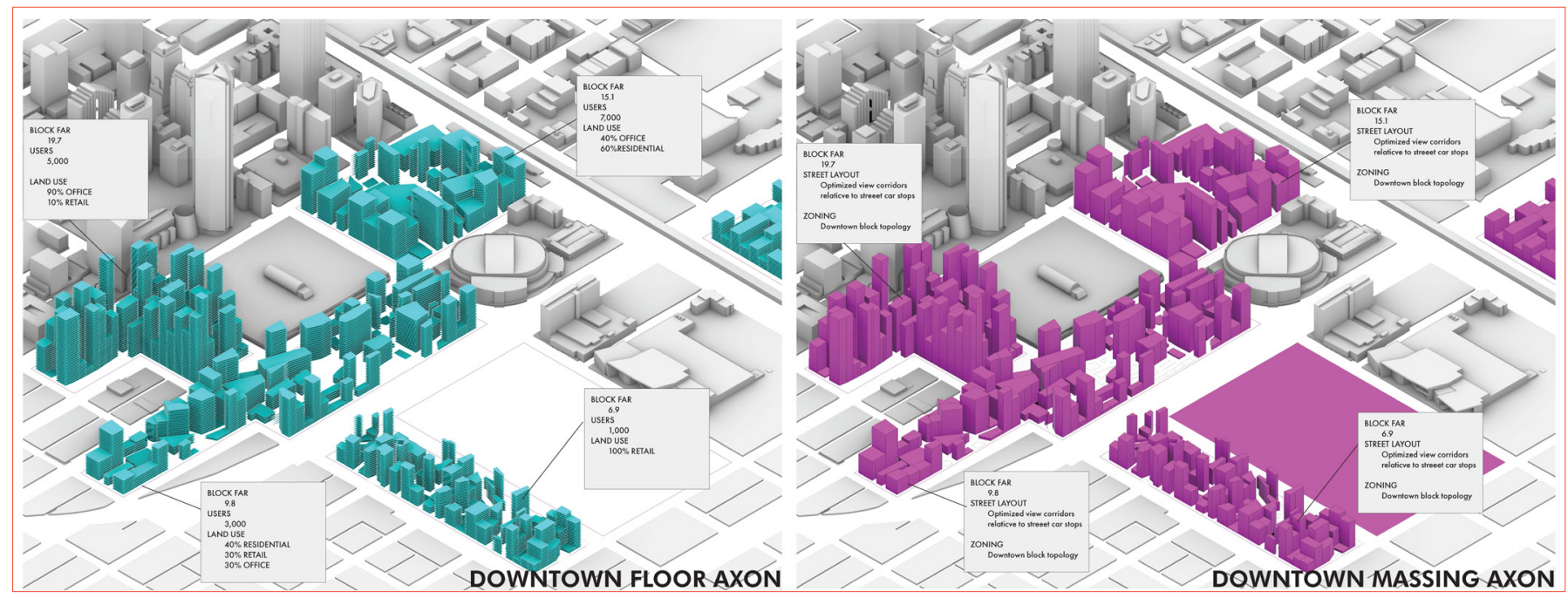

Figure 7. BLOCK GENERATIVE MODELLING. 


\section{THE RESULTS}

Specific deliverables for accessibility, walkability, and pedestrian movement analysis were developed and produced. This attempted to answer the fundamental questions above. Simultaneously, it established tangible information on how many surrounding destinations could be reached from the location within a given network radius, based on the types of destinations: transit, businesses, and residences. Three entities were used in the research reports: balancing different uses and the urban landscape, commuter flow and gravitational force, and socio-economic dynamics. This simulation, Urban Topological Analysis, and Accessibility proposed ecological remediation of existing urban areas and reexamined the current course of urban renewal strategies for Oklahoma City Streetcar.

\section{INTERACTIVE PODIUM}

During the research project with the OKC Planning Department, the team strived to include community members in the decisionmaking process. Communicating effectively is imperative for any type of research, but working with non-expert stakeholders posed unique challenges, such as communicating various solutions and visualizing the three-dimensional nature of urban form. In order to explore broader solutions and achieve faster feedback, it is critical to design an effective way of interacting not only within the team but also with
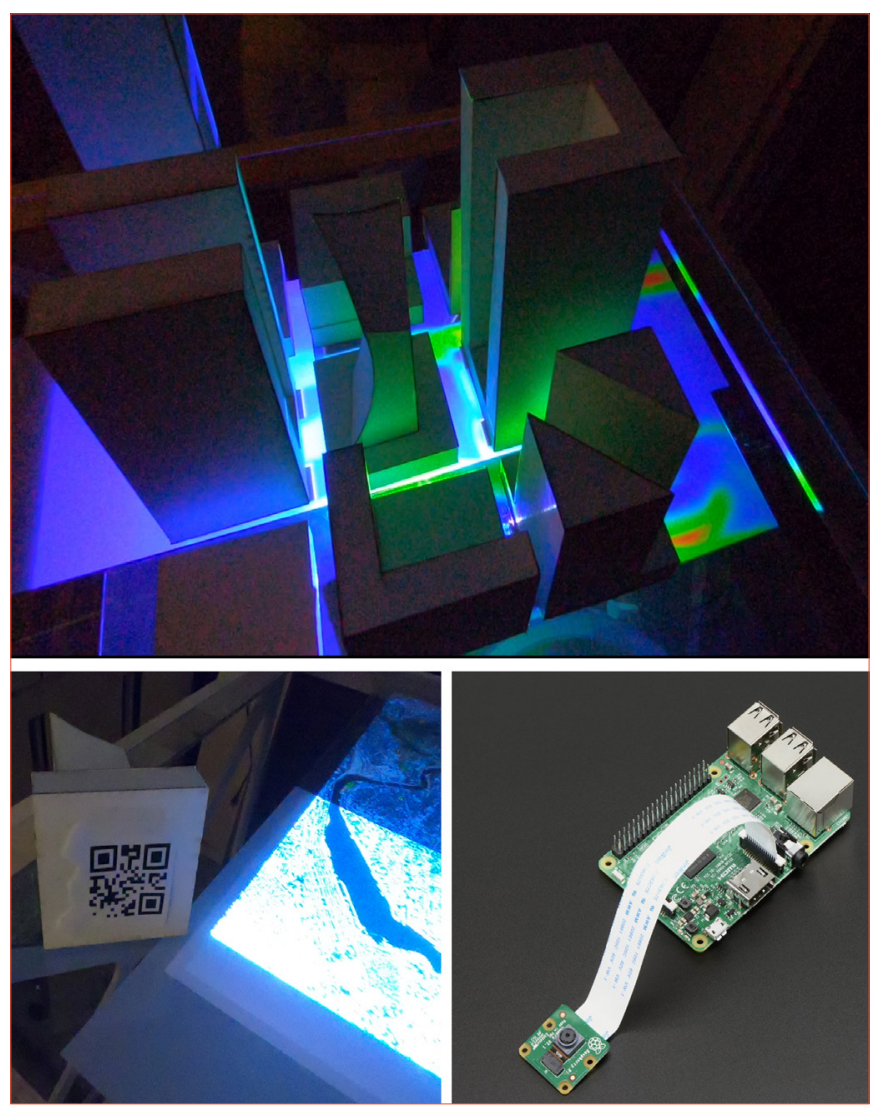

Figure 8. INTERACTIVE PODIUM (Bottom right: Raspberry Pi 4 \& Camera) ${ }^{11}$ the community. In response to this need, the proposed research grant, Interactive Podium was awarded by the Office of the Vice President for Research at Oklahoma State University. This proposal is for Research Project Grants in Humanities-, Arts-, and Design-based Disciplines awarded on the intellectual significance and/or artistic merit of the project, including the project's potential contribution to the field and potential impact.

This project aims to enhance interdisciplinary research by using embedded computing technology to create a visual platform for interaction between users. This data visualization tool provides planning analysis for the built environment, from interior space to cityscapes. City planning and spatial analysis of complex interior programs like schools, hospitals, and manufacturing facilities would be immensely enhanced by this visual, intuitive, and interactive research tool. This AR projection a tool will augment discussion by overlaying current conditions and analytical data onto a scaledmodel by projector. New layers of information can be added to the model to create and test artificial environments to simulate and analyze potential uses. Providing an interactive planning tool like this will increase interaction between researchers and users. It overcomes the outdated top-down decision-making process, allowing early participation of users in the process of projects. This project provided an interactive and responsive tool for mixed users (in this case, community members, architects, planners, and city officials). It also delivered an optimal solution for improving the communication methods, interactivity of the project team, and competent involvement of the community. The project goals were: making an intuitive and tangible tool for exploration between experts and nonexperts, creating a visual simulation to help users communicate and to enhance collaborative decision-making, and designing an interactive system for non-expert stakeholders to define and achieve their goals efficiently.

The outcome of the project was fabricated as a physical podium to visually communicate the design and decision-making process for experts and non-expert stakeholders in the early stages of planning and design projects. The podium's interactivity offers an effective teaching tool for a wide number of disciplines, from Architecture, Engineering, Geography, Interior Design, Urban Economics, and beyond. Naturally, the project is an interdisciplinary research and teaching tool, allowing users to spatially visualize possibilities, as well as graphically represent various data sets. ${ }^{12}$

Downtown Oklahoma City is forward-looking in its aim to be a more environmentally conscious and walkable city. Therefore, its urban form should explore deviations from monotonous street grids in favor of less rigid and more spontaneous paths which heighten pedestrian awareness. Higher density and mixed-use zoning would increase walkability of Oklahoma City by concentrating people and services within close proximity to each other. Oklahoma City could be a catalyst for progressive urban development in the Midwest. 
This interdisciplinary project provided clues for developing an effective platform to bring diverse entities together. The level of complexity in the future of the profession demands an asynchronous planning approach to accommodate various aspects and disciplines in current urban issues. This complements current architectural research and urban planning methods, while generative methods continue to evolve in the spectrum of architecture in general. Urban data research methods demonstrate how we see and understand the city via the flow of spatial data. The research and the grant project together delivered simulation to inform the design and strengthen the decision-making process and visualization to predict the success or challenges of pedestrian and vehicular circulation, conservation of land, and evaluation of city grid plans.

\section{Notes}

1. Andres Sevtsuk, Urban Network Analysis for Rhinoceros 3D (Cambridge: City Form Lab, 2018), 7-11.

2. Ibid, 83-116.

3. Metropolitan Area Projects Plan 3 (MAPS 3), https://www. okc.gov/government/maps-3/about-maps-3, MAPS 3 is a capital improvements program in Oklahoma City that uses a one-cent, limited-term sales tax to pay for debt-free projects that improve our quality of life. http://okcstreetcar.com/, In 2005, EMBARK's Board of Trustees approved a regional fixed guideway plan aimed at strengthening community connections, supporting economic growth and developing new mobility options. As a result, in 2009 Oklahoma City voters said "yes" to a \$135-million modern transit initiative to build a modern streetcar system and multimodal transportation hub. Led by a resident-based committee, the Oklahoma City Streetcar began its planning and design in 2010 and broke ground in February 2017.

4. Jean-Paul Rodrigue, The Geography of Transport Systems (New York: Routledge, 2017), Chapter 8, https:// transportgeography.org/?page_id=4609.

5. Sevtsuk, Urban Network Analysis, 83-116.

6. Ibid, 83-116.

7. U.S. Census Bureau QuickFacts Oklahoma City, Oklahoma https://www.census.gov/quickfacts/fact/table/ oklahomacitycityoklahoma/PST045218

8. Sevtsuk, Urban Network Analysis, 83-116.

9. DeCodingSpaces Toolbox for Grasshopper, https://toolbox. decodingspaces.net/, DeCodingSpaces Toolbox is a collection of analytical and generative components for algorithmic architectural and urban planning. The toolbox is free software released by the Computational Planning Group (CPlan) and is a result of long term collaboration between academic institutions and praxis partners across the globe with the common goal to increase the efficiency and quality of architecture and urban planning.

10. Vishaan Chakrabarti, A Country of Cities: A Manifesto for an Urban America (New York: Metropolis Books, 2013), 34-87.
11. Raspberry Pi Foundation, https://www.raspberrypi.org/.

12. Andy Kirk, Data Visualisation: A Handbook for Data Driven Design (Los Angeles: SAGE, 2016), 157-160, 332-334. 